\title{
Towards a Definition of Role-related Concepts for Business Modeling
}

\author{
L.O. Meertens, M.E. Iacob and L.J.M. Nieuwenhuis \\ Department of Information Systems \& Change Management \\ University of Twente, School of Management and Governance \\ Enschede, The Netherlands \\ 1.o.meertens@utwente.nl, m.e.iacob@utwente.nl,1.j.m.nieuwenhuis@utwente.nl
}

\begin{abstract}
While several role-related concepts play an important role in business modeling, their definitions, relations, and use differ greatly between languages, papers, and reports. Due to this, the knowledge captured by models is not transferred correctly, and models are incomparable. In this paper, we provide a meta-model and definitions for several role-related concepts based on the practice of existing modeling languages and ontological analysis. This forms a basis for creating comparable, formal business models, which enable further enterprise engineering, in a repeatable way.
\end{abstract}

Role, business modeling; enterprise engineering; stakeholder; concept; definition; meta-model

\section{INTRODUCTION}

Innovations in IT projects often suffer from so-called pilot-illness. Many such projects successfully deliver a working pilot or system that is claimed to deliver more efficiency and more functionality, which eventually fails to be absorbed into the real life settings. Most of the time this issue is caused by yet another technology push, which disregards a proper analysis from a business perspective and does not put the problem in its context. Especially in complex environments (e.g., healthcare), such projects fail to take into account the business aspects that are required for a technological innovation to become a success in real-life settings. Usually, questions such as "who benefits from the product?", and "who will pay for it?" are not included in the design of new IT products. Yet, they may have a huge impact on the requirements for the end system. Especially when the answers to the above questions may concern multiple stakeholders, the chance that the product is adopted and implemented is severely limited.

This quick analysis, allows us to draw two conclusions:

1. the main aim of such systems should be to help reduce costs;

2. there is a growing need to replace the "technology push" style in motivating the design of new systems.

Currently, "problems" are artificially created for an existing technological solution. This style should be replaced by approaches in which business models and requirements (i.e., the actual problems) are the driving mechanism of the solution design. If we take a formal specification perspective, the above mentioned problem can be translated into the need of developing a formal method to align and integrate business models with design models, such as enterprise and software architecture models. This should help us avoid building economically non-viable systems, since their design is based on (and derived from) a viable business model.

In this paper we argue that, in order for such a method to be successful, we have to investigate the constructs that are the interface between these two modeling domains (business modeling and enterprise engineering), namely, role and rolerelated concepts. Such concepts are present in both business models and enterprise models, as explained below. Creating business models starts with an identification of the "entities" that are of interest in them. An often-heard name for this is "stakeholder analysis". This terminology suggests that such entities in the business model are the "stakeholders". Most modeling languages for enterprise engineering, however, do not have the concept of stakeholder but those of actor, role, person, system, agent, user, etc. In casual speech, people seem to know what the terms mean and what the differences between them are. However when it comes to models requiring formal definitions, it quickly becomes clear that people have different conceptions of the same terms, and the general understanding of them is of little use.

\section{A. Formalizing role-related concepts}

From our point of view, the general understanding is neither sufficient nor acceptable, since we focus on formal specifications of such concepts. Therefore, we need a precise understanding for a specific domain. In this paper, we propose a meta-model and definitions for several role-related concepts; the Role Meta-Model (RMM).

According to Zhu and Zhou [7], "There should be more specific applications applied into different branches of information systems. Additional studies are required regarding roles as basic concepts that are more relevant to that of management." For example, Almeida and Guizzardi [1] provide a semantic foundation for role-related concepts in enterprise engineering based on ontological analysis. The reference ontology used by Almeida and Guizzardi as a basis for their research is the UFO. They also provide several other examples of definition and consolidation efforts in other areas, such as object-oriented programming, and UML.

In this paper, we extend their work, as well as that of others $[1,2,4,7]$ and propose a meta-model and definitions for several role-related concepts that are rooted in the 
practice of existing modeling languages and are intended to serve as a formal basis for business modeling, and for relating business modeling with enterprise engineering. Furthermore, we address one of their suggestions for further research: the whole/part-relation. The whole/part-relation is essential for stakeholder analysis, as it is both a way to identify stakeholders, and to group them.

\section{B. Scope of role-related concepts}

We start by setting the scope of this research to the specific application of roles in the domains of stakeholder analysis for business modeling and enterprise engineering. We argue that these two areas need to share a common understanding of the role concept in order to be possible to align business models with enterprise models.

Recently, Zhu and Zhou [7] surveyed the landscape of role-related research in information systems. They found several perspectives that apply to roles: reasons, players, content, specification, assignment, and relationships. These perspectives help us to position and scope our work more precisely by defining which type of roles we are interested in and explicitly exclude the others. Subsequently, after an examination of these perspectives we conclude the following:

- Three of the four reasons identified by Zhu and Zhou apply in our context. Separation of concerns and modeling interaction are some of the main reasons to do enterprise engineering in the first place. Classification of entities helps us identify the right (groups of) stakeholders. Evolution, on the other hand, is not of immediate interest for this research.

- From Zhu and Zhou's five players we drop the object-oriented ones: object and operation. Agent, human (sub-set of agent in our view), and groups of the other two players are taken into account.

- The perspective of contents requires that roles contain requests and (provide) services. In our work, these are both important for roles, as they model their rights and responsibilities. As we target a level of abstraction far above implementation, at first we do not need roles to have a concrete specification, and we consider that having role interfaces specified would be sufficient. Decomposition may lead to a specification that is more concrete though.
- Assignment of roles is of interest to us mainly from the allocation perspective. The description by Zhu and Zhou on instantiation of roles is much closer to implementation, than the definition of instantiation we will use in our model and therefore not of interest to us. Next to allocation, constraining by roles is also of interest to us, as it illustrates which players are allowed to play which roles.

- The only relationship between roles that is relevant in the context of our research concerns the fact that they may inherit from each other (in a decomposition/hierarchy). Conflict, qualification, and place are dropped, as they mainly serve to constrain roles with respect to certain aspects (such as, time and place), and are therefore irrelevant in this case.

Both Zhu and Zhou [7] and Loebe [4] provide a treehierarchy for the classification of roles. Zhu and Zhou's taxonomy is more detailed. However, its primary focus is on system engineering, which makes it less suitable for our purposes. Our conception of roles could probably best be positioned as one of the nodes high up in their taxonomy tree, and could be identified as either "modeling roles" or the top-level "social roles". In Loebe's tree, the "social role" seems to be the best choice from a stakeholder perspective. However, the "processual role" better fits the domains of business modeling and enterprise engineering, since it has a stronger link to the important aspect of behavior. As it is also better formalized, we choose to use this classification.

\section{Outline}

Above, we limited the scope of our research to roles in the domains of stakeholder analysis for business modeling and enterprise engineering. The next section addresses the features of roles. There we also discuss existing definitions from related research. After introducing the meta-model, we relate our concepts to Osterwalder's business model ontology (BMO) [5] and to the enterprise modeling language ArchiMate [6]. In order to illustrate a potential use of the meta-model, we handle a small case in the care sector in section IV. We conclude with a discussion of the benefits, drawbacks, and limitations of our approach and with some pointers to future work.

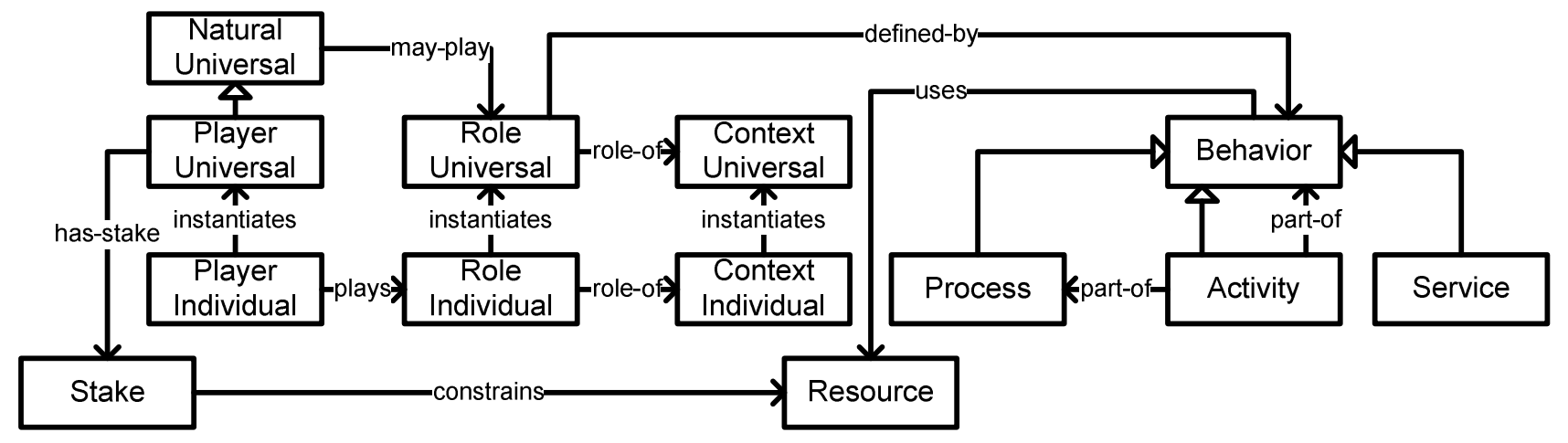

Figure 1. Meta-model overview. Grouping is left out for clarity. An open-headed arrow indicates the specialization relationship 


\section{META-MODEL AND DEFINITIONS}

In this section, we define the core concepts included in the role meta-model (RMM) that we propose. The full RMM is depicted in Fig. 1. In the following subsections, we discuss several parts of this model and we conclude with an overview table containing the constructs' definitions.

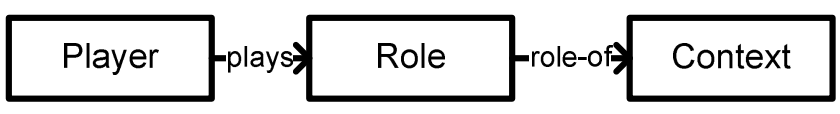

Figure 2. Simplified view on roles.

\section{A. Core of the model}

The core of the RMM consists of three concepts: player, role, and context. A player plays a role, and a role exists only in relation to a certain context. For example, a man (player) can play the role of father (role) for a son (context). Each of the three concepts has a universal and individual variant. Individuals are entities with a unique identity. They are an instance of a universal. Universals capture general aspects of a similar group of individuals (adapted from [1]). In objectoriented terms, individuals correspond to objects, and universals to classes [4]. The previous father-son example handled universals. An example of an individual is Peter who is the father of Jason. A universal and individual level can be included in a similar fashion for all the concepts that we add in the following sections.

A subtle detail that may need further clarification is the "natural universal" [4]. This concept is a super-type of player universal. It helps identifying (and restricting) the type of player universals that may (not must!) play a certain role. For example, only men (not women) may play the role of father. However, not all men actually play the role of father. The natural universal may be interpreted as a potential player. In this sense, it can help in for example design processes where the design starts from a behavioral perspective. After specifying the behavior, roles can be derived. Natural universals indicate which players could play these roles. The simple alternative, creating a direct relation between role and player, does not suffice. It does not allow the distinction between having the potential to play a role, and playing the role.

Loebe [4] recognizes that the universal-level interpretation of the plays-relation differs from the individual meaning. The universal meaning restricts the relations individuals may have. Therefore, we have decided to drop the symmetry, and rename the universal-level plays-relation to "may play". This represents the fact that natural universal

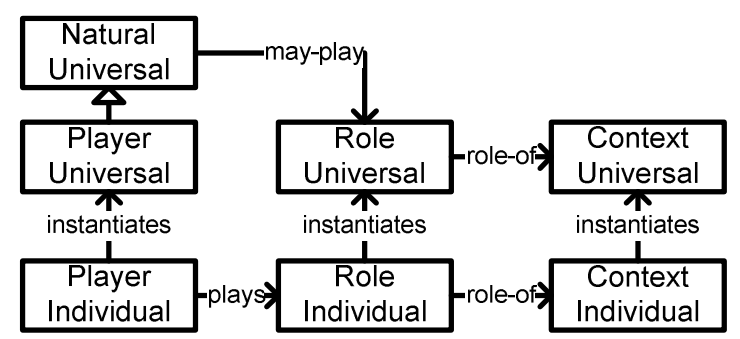

Figure 4. Core of the model. Primitive adaptation of Loebe [2007, p133]

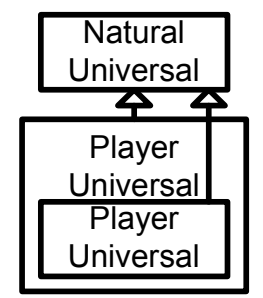

Figure 5. Grouping, the part-of relation. The part-of relation is represented by an entity withtin another entity.

may play a role, and not must or necessarily are playing it.

Universals are one way of grouping in a stakeholder analysis. This manner of grouping allows us to generalize several individuals to one concept. For example, instead of listing all the employees of a company as individual stakeholders, we can use "the" universal employee as a stakeholder. The universal employee is an appropriate stakeholder as the individuals it encompasses have common aspects. A universal is not a whole/part-relation. We discuss those next as (de-)compositions.

\section{B. Extension for stakeholder analysis: decomposition and stakes}

Each of the three core concepts (role, player, context) is (de-)composable. A grouping is possible according to any property of the concepts. As roles are a design concept, we get to choose the level of detail in our models. This is where decompositions / whole/part-relations are important. Most often, concepts are not atomic; they can be separated into different parts. Even if they are atomic, they are part of a greater whole. For players and behavior, this is intuitive. An organization can be a player, but it may consist of several business units (sub-players). A process (behavior) is a partial ordered set of actions (sub-behavior). From this, we can derive the division of roles into sub-roles. The organization as a whole may play a role (e.g. buyer) in a transaction (a specialization of behavior) with some supplying company (context). The business units may individually perform actions within the transaction, for example ordering. These actions define a sub-role (orderer).

For a simple listing of stakeholders, the concepts of players (universal and individual) and roles, together with decomposition, are almost sufficient. A subtle detail that may add some clarity is the "natural universal" [4]. This concept helps identifying (and restricting) the type of players (universal) that may (not must!) play a certain role. A stakeholder is a player individual, player universal, or a composition of one of these concepts.

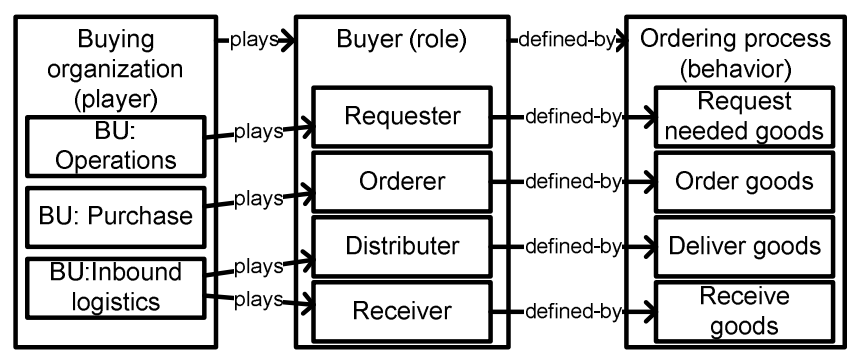

Figure 3. Grouping example. The part-of relation is represented by entities withtn another entity: The Requester (sub-)role is a part-of the Buyer (super-)role. 


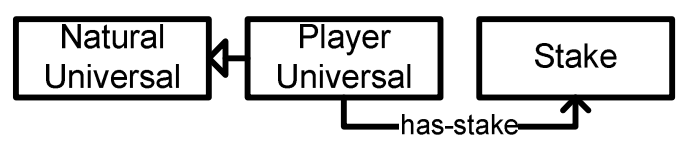

Figure 6. Stakeholder, has-stake relation.

For a more advanced stakeholder analysis, the first concept to add is the stakeholder's actual stake(s). In general, the stake is the reason to participate in certain behavior. The stake can be articulated further from different perspectives, for example as goal modeling, which is outside the scope of this paper. However, we will illustrate its place in enterprise engineering and business modeling. In quantitative business models, the stakes are quantified in terms of (financial) aspects of revenues and costs, while value propositions capture the qualitative parts of stakes. In enterprise engineering, the stake is seen as a "concern" a stakeholder has [3].

\section{Extension for enterprise engineering: specialized behavior}

Behavior consists of actions or reactions (possibly related to each other) of a player in relation to the environment. A role groups specific behavior. This specific behavior can be of either consuming or providing nature. In addition, this behavior may assume interaction between two (or more) roles, in which one role provides some value for the other role. One role provides (responsibility), the other consumes (rights). In such case, we say the behavior is an interaction. This gives an indication of the external visibility of the behavior. When performing a stakeholder analysis and designing business models one is mostly interested in this type of externally observable behavior. Often, providing this kind of externally observable behavior is named a service. In enterprise engineering, one of the two roles is often implicit, as the organization or system under investigation is playing the (providing) role.

Decomposition of behavior is especially important in enterprise engineering. Whole branches of research are dedicated to this, for example business process management.

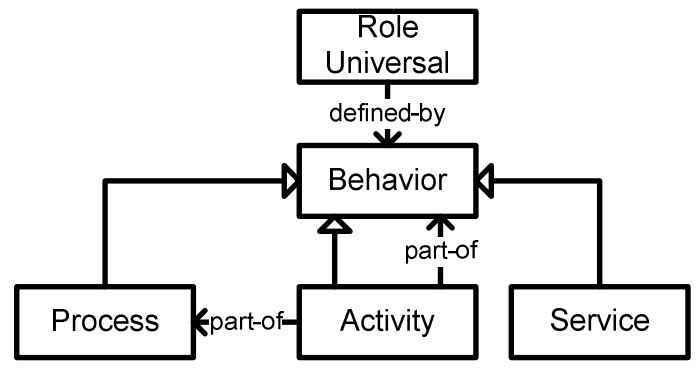

Figure 7. Specialization of behavior.

The plethora of notations available supports various (overlapping) concepts. From those, we pick a few to specialize the behavior concept. As said before, one general behavior concept is a service, for which we adopt the ArchiMate definition: externally visible behavior, with some value for a consuming role. Another specialization is that of activity: behavior usually consists of smaller parts, which we call activities. Although not elaborated in the RMM further, we also mention here a behavior concept, common in

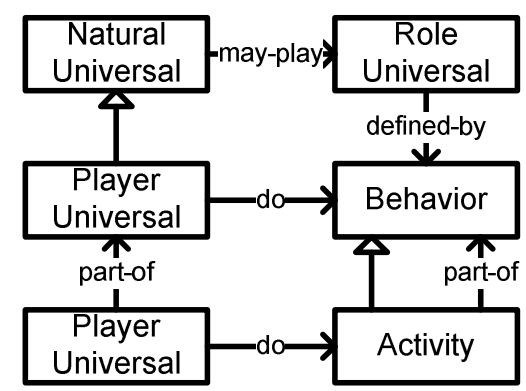

Figure 8. Specialized behavior in combination with grouping enterprise engineering, namely that of process, which is defined as a partially ordered set of activities. A process may realize a service. Further specialization of behavior is outside the scope of this paper.

\section{Extension for business modeling: resource}

As discussed before, stakes indicate costs and revenues, while behavior indicates what happens. A link between them, which is especially interesting for business modeling, is the concept of resource. A direct connection to role is that human resources (and other agents) can be modeled as roles. Note that behavior uses resources, and acquiring resources requires making costs, while selling resources may provide revenue.

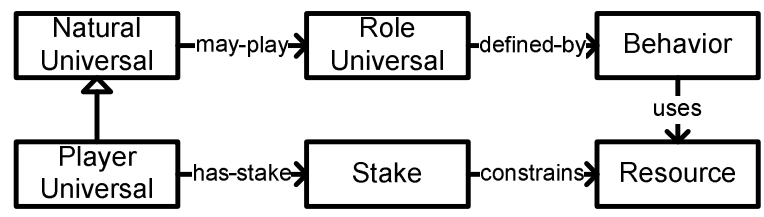

Figure 9. Resources, constrains and uses relations.

\section{E. Definitions}

Defining role-related concepts is difficult, as in natural language many terms have overloaded and overlapping connotations. On the one hand, one word can have many meanings, while on the other hand different words can have the same meaning. This is not only the case for the terminology, but it also holds for applying the theory in practice. We often use the same word for both the actor and the role, as we tend to define people by what they do. Until now, also standards did not provide a proper solution to this problem. Furthermore, the many individual standards contain definitions that do not match. We aim to resolve some of these issues in this section by providing definitions for rolerelated constructs in tables I and II.

TABLE I. DEFINITIONS OF ROLE-RELATED CONCEPTS

\begin{tabular}{|l|l|l|}
\hline \multicolumn{1}{|c|}{ Concept } & \multicolumn{1}{|c|}{ Definition } & Other terms \\
\hline Role & A grouping of specific behavior & $\begin{array}{l}\text { ActorType, } \\
\text { Actor }\end{array}$ \\
\hline Player & $\begin{array}{l}\text { A player is something (person, } \\
\text { department, active piece of software) } \\
\text { that } \\
\text { fulfils roles. }\end{array}$ & $\begin{array}{l}\text { Actor, } \\
\text { stakeholder, } \\
\text { participant }\end{array}$ \\
\hline Context & $\begin{array}{l}\text { Thee conditions and circumstances } \\
\text { that are relevant to an event, fact, etc. }\end{array}$ & $\begin{array}{l}\text { Environment } \\
\text {, behavior }\end{array}$ \\
\hline Behavior & Actions or reactions (possibly related & Process, \\
\hline
\end{tabular}




\begin{tabular}{|c|c|c|}
\hline & $\begin{array}{l}\text { to each other) of a player in relation to } \\
\text { the environment. }\end{array}$ & service, step \\
\hline $\begin{array}{l}\text { Natural } \\
\text { universal }\end{array}$ & $\begin{array}{l}\text { natural universals are a means to refer } \\
\text { to potential players of a role }\end{array}$ & Actor type \\
\hline $\begin{array}{l}\text { Player } \\
\text { universal }\end{array}$ & See player. & $\begin{array}{l}\text { Actor type, } \\
\text { participant }\end{array}$ \\
\hline $\begin{array}{l}\text { Player } \\
\text { individual }\end{array}$ & $\begin{array}{l}\text { An instantiation of a player universal, } \\
\text { with a unique identity. }\end{array}$ & \\
\hline Role universal & See role. & Actor type \\
\hline $\begin{array}{l}\text { Role } \\
\text { individual }\end{array}$ & $\begin{array}{l}\text { An instantiation of a context } \\
\text { universal. }\end{array}$ & $\begin{array}{l}\text { Qua- } \\
\text { individual }\end{array}$ \\
\hline $\begin{array}{l}\text { Context } \\
\text { universal }\end{array}$ & See context. Any natural universal. & \\
\hline $\begin{array}{l}\text { Context } \\
\text { individual }\end{array}$ & $\begin{array}{l}\text { An instantiation of a context } \\
\text { universal. }\end{array}$ & \\
\hline Stake & An interest, often financial & $\begin{array}{l}\text { Goal, } \\
\text { objective }\end{array}$ \\
\hline Resource & $\begin{array}{l}\text { A source of economic wealth, esp of a } \\
\text { country (mineral, land, labour, etc.) or } \\
\text { business enterprise (capital, } \\
\text { equipment, personnel, etc.) }\end{array}$ & \\
\hline Process & $\begin{array}{l}\text { A collection of steps taking place in a } \\
\text { prescribed manner and leading to an } \\
\text { objective. The prescribed manner may } \\
\text { be a partially ordered sequence. }\end{array}$ & \\
\hline Service & $\begin{array}{l}\text { Externally visible behavior, providing } \\
\text { value to some role. }\end{array}$ & \\
\hline Activity & Any specific deed, action, pursuit, etc. & Step \\
\hline Value & $\begin{array}{l}\text { The desirability of a thing, often in } \\
\text { respect of some property such as } \\
\text { usefulness or exchangeability: worth, } \\
\text { merit, or importance }\end{array}$ & Worth \\
\hline Stakeholder & A player universal with a stake. & \\
\hline
\end{tabular}

\begin{tabular}{|l|l|l|}
\hline Uses & $\begin{array}{l}\text { The uses relationship models the } \\
\text { use of resources by behavioral } \\
\text { concepts. }\end{array}$ & $\begin{array}{l}\text { Requires, used-by, } \\
\text { access, requires }\end{array}$ \\
\hline (Do) & $\begin{array}{l}\text { (shortcut from player to behavior, } \\
\text { skipping role) }\end{array}$ & $\begin{array}{l}\text { Performs, } \\
\text { participates-in }\end{array}$ \\
\hline
\end{tabular}

\section{MAPPING THE RMM TO ARCHIMATE AND OSTERWALDER'S BMO}

The meta-model has to comply to and integrate with existing modeling practice. This forms a basis for creating comparable, formal business models and enterprise models. To demonstrate that the RMM indeed has these characteristics, we show that it can be seamlessly mapped with the two modeling domains defined as scope of this research: business modeling and enterprise engineering. To this purpose, we show that a connection with business models is feasible, by mapping Osterwalder's Business Modeling Ontology (BMO) [5] to the RMM. The link with enterprise engineering is made by mapping the meta-model onto ArchiMate's meta-model [6].

\section{A. The Business Modeling Ontology}

Osterwalder's BMO contains various role-related concepts. Some of the BMO terms match those we propose in the meta-model. However, the definitions and scope of the terms differ. Furthermore, for three concepts in the BMO, the meta-model provides no direct mapping. These are distribution channel, costs, and revenue. Player universal captures several concepts of the BMO, most importantly the actor, which can be the firm itself or a partner. Two other concepts that it captures are the target customer and human resource. Each of these may also be instantiated to a player individual. The "firm itself" exemplifies this. As with all player/natural universals, these concepts may also serve as the context for some role.

For example, a partner can play the role of supplier if the firm itself is the context. However, if you view the partner as context, the firm itself plays the role of buyer.

TABLE III. BMO - RMM MAPPING

\begin{tabular}{|l|l|}
\hline \multicolumn{1}{|c|}{ BMO } & \multicolumn{1}{c|}{ Meta-model } \\
\hline Actor (self or partner) & $\begin{array}{l}\text { Player universal (or individual) (also possible } \\
\text { as context) }\end{array}$ \\
\hline Human Resource & $\begin{array}{l}\text { Player universal (or individual) (also possible } \\
\text { as context) }\end{array}$ \\
\hline Customer & $\begin{array}{l}\text { Player universal (or individual) (also possible } \\
\text { as context) }\end{array}$ \\
\hline (Non-human) Resource & Resource \\
\hline Relationship & Role \\
\hline Activity & Behavior (any) \\
\hline Value proposition & Stake + Behavior \\
\hline Connections) & Roles \\
\hline Revenue & - \\
\hline Costs & - \\
\hline Channel & - \\
\hline
\end{tabular}




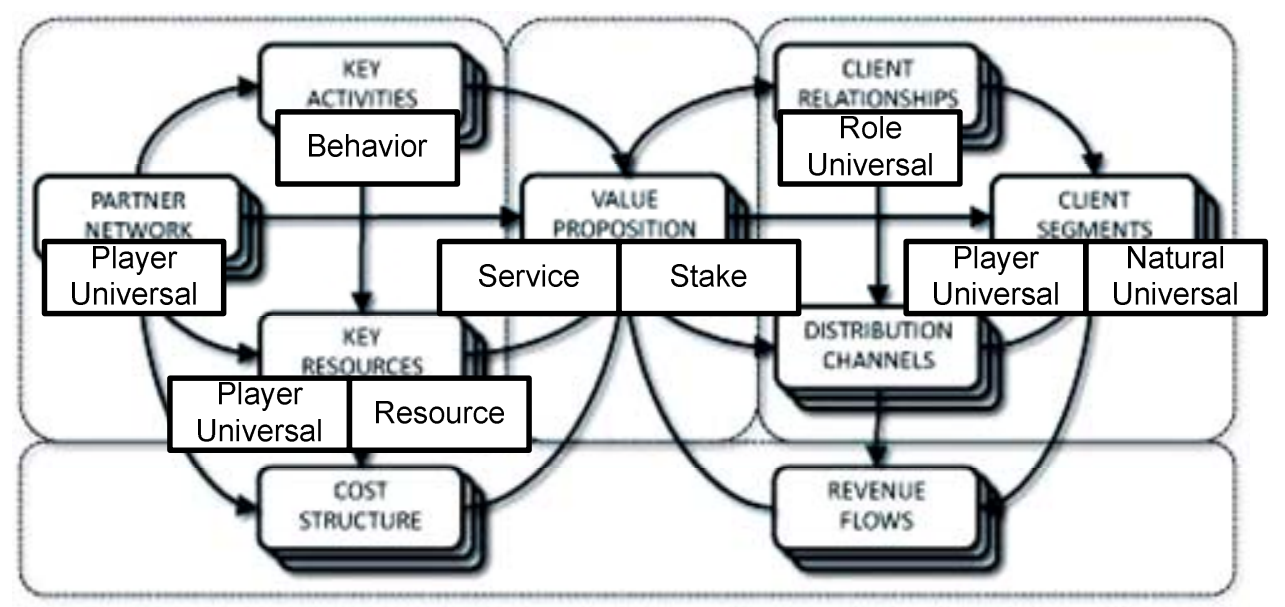

Figure 10. The BMO canvas, including the RMM concepts that map to some of them directly.

Much of the resource concept from the BMO is captured by resource from the meta-model. The other part is human resources as described above. The BMO's key activites concept encompasses all of the behavior in the meta-model, not only the activities. The value proposition lists the stakes and specifies which services contribute to them. The relationship concept is one type of role universal ("relational role"-type according to Zhu and Zhou [7]). Other roles are not identified as concepts in the BMO, yet they are present in the form of connections between the concepts. An example is the role of supplier that a partner may play in the context of the firm itself. The behavior of supplying a certain resource defines the role. In the $\mathrm{BMO}$, the role of supplier is modeled as a connection between the specific resource and the supplying partner.

\section{B. ArchiMate}

In order to show how the RMM relates to enterprise engineering, we examine the relationship between constructs identified in the RMM and the constructs defined in the ArchiMate language, which is the standard for enterprise architecture modeling [6]. We do this by establishing a mapping (presented in table IV) between corresponding constructs of the RMM and the ArchiMate meta-model (Fig. 11 depicts the relevant port of it).

A business actor can be part of another business actor according to ArchiMate's description. Their core feature is that they (are capable of) perform(ing) behavior. Besides that, you can assign them to one or more business roles. The examples given indicate that an actor can be either an individual player or a universal player. From a particular human to a grouped, abstract type of organization.

The same description defines a business role as specific behavior of an actor. The role implicitly indicates certain responsibilities and skills that an actor playing the role must provide. An actor may have multiple roles. In turn, a role may be assigned to multiple processes or functions. A role may use interfaces, and interfaces can be part of roles. From an organizational perspective, roles are for example also useful for the division of labor.

The player universal and player individual are both covered by ArchiMate's business actor concept. ArchiMate makes no distinction between them. This also holds for roles and context. The concept of natural universal has several possible mappings. All of ArchiMate's structural concepts may represent it. As context can exist of any natural universal, any structural concept may serve as context too.

TABLE IV. RMM - ARCHIMATE MAPPING

\begin{tabular}{|l|l|}
\hline \multicolumn{1}{|c|}{ Meta-model } & \multicolumn{1}{c|}{ ArchiMate } \\
\hline Player Universal, Player Individual & Actor \\
\hline Role Universal, Role Individual & Role, Interface, Collaboration \\
\hline Context Universal, Context Individual & Any structure concept, or event \\
\hline Natural Universal & Any structure concept \\
\hline Stake & - \\
\hline Resource & $\begin{array}{l}\text { Actor, Node, Network, Device, } \\
\text { Component, ... }\end{array}$ \\
\hline Behavior & Any behavior except event \\
\hline Process & Process \\
\hline Activity & Behavior, Function, Interaction \\
\hline Service & Service \\
\hline
\end{tabular}

The business role in ArchiMate maps to the role universal and role individual in our meta-model. However, ArchiMate has two other concepts that are specializations of role universal. A business collaboration in ArchiMate is the grouping of two or more business roles. This is another concept specifying a role universal, specifically a decomposable role universal. Two or more roles are part of another role. A business interface may be part of a business role and used by a business role according to ArchiMate. This indicates that a business interface is another specialization of role universal. It is a lower-level role, which specifies only a sub-set of the behavior of the higher-level role. 


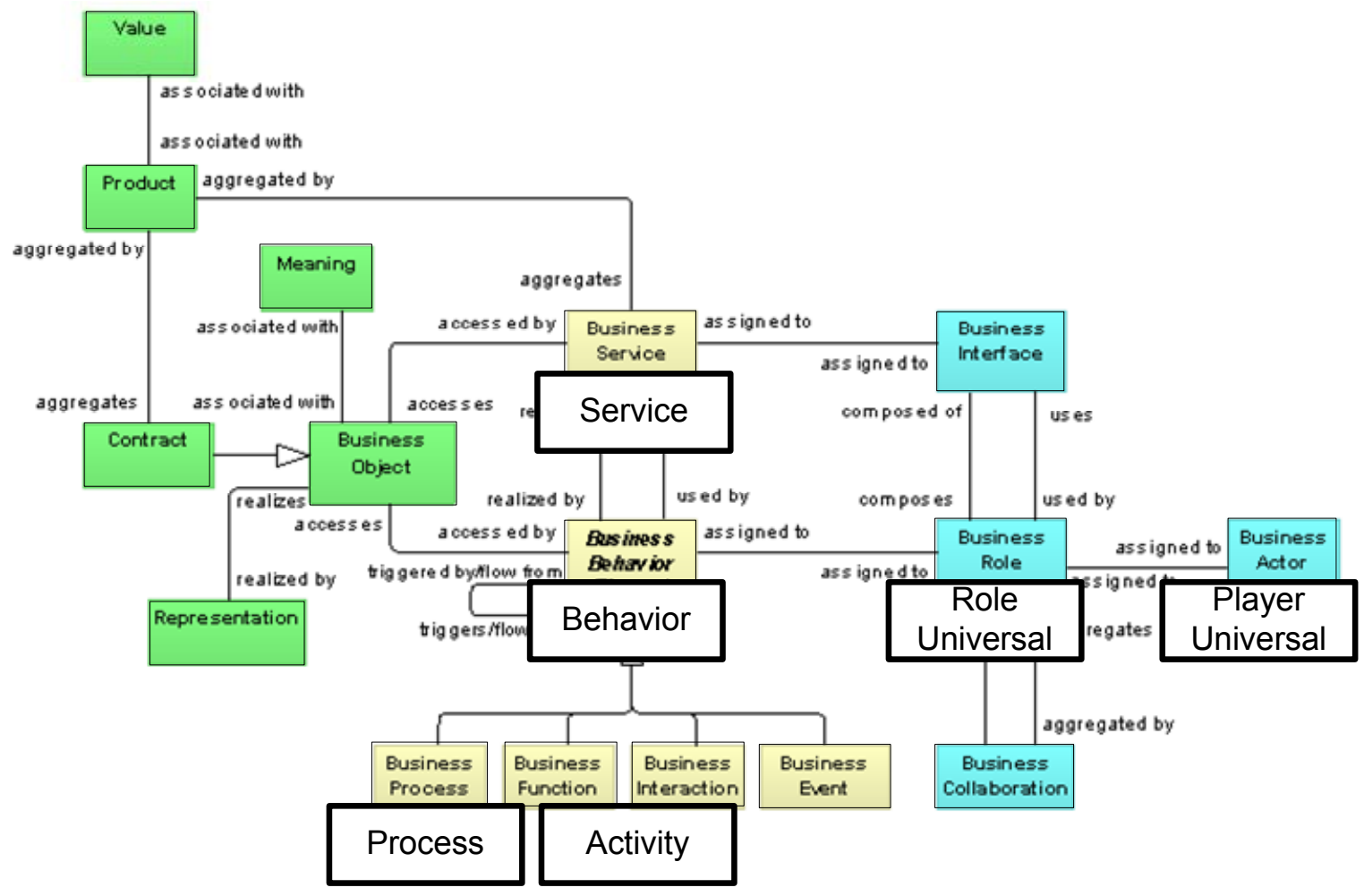

Figure 11. ArchiMate's Business layer meta-model, including the RMM concepts that map to some of them directly.

Any of ArchiMate's behavioral concepts map to the behavior concept in the meta-model, with the exception of business event. This concept does not present actual behavior, but rather a certain (trigger from the) context. Two out of three specializations in the meta-model have counterparts in ArchiMate. Service maps to business service, and process maps to business process. Activity has no oneon-one mapping, but can be represented by the general behavior element, or the function or interaction specializations.

It is only partly possible to represent resources in ArchiMate. For IT components, several concepts exist at the application and technology layer, for example, system software, device, and network. Similar to the BMO, actors may represent human resources. All other resources have no mapping. No suitable mapping is available for stake either.

\section{EXAMPLE SCENARIO}

A scenario based on Johanna demonstrates how the RMM can be applied in both business modeling and enterprise engineering, and connect the fields. Sister Johanna is a nun, member of a congregation that has only few members left in this part of Europe. She is 66 years old and has been in a wheelchair for nine years now. Most medical problems are due to the condition of her bones, they are too weak. In addition, she has some problems that she perceives as "minor", and are countered by medicines. She started to do youth work for the congregation many years ago. Among other things, the Youth Council organizes youth camps and weekends in the countryside. Sister Johanna helps running these still. Sister Johanna leads an active life, despite the fact that she can only move in a wheelchair. She is dependent on technology for communication - and for making sure that she does not forget things.

The setting for the scenarios is the suburban area Hogre Heights $(\mathrm{HH})$. It has a community centre with a range of facilities, including a restaurant, shop, hairdresser, swimming pool, and primary school. The $\mathrm{HH}$ home care organization is located in the community centre and delivers various forms of care. There is a nursing home and sheltered accommodation attached to the community centre, but also home care is delivered in the neighborhood. A communication and information infrastructure has been rolled out in $\mathrm{HH}$ two years ago.

On top of this infrastructure, the $\mathrm{HH}$ home care organization provides extra services. One of the important services for Johanna is the reminder service. The service helps her remember appointments, events, and to take her medicines. Fig. 12 shows an ArchiMate model for the service's architecture.

Johanna is a clear example of a player individual. She plays several roles and has an own identity. Within the context of the home care organization, she plays the role of patient. Within the Youth Council, she plays the role of organizer. Only the people who have a contract with the home care organization (clients) may play the role of patient. These clients are a natural universal of which Johanna is an instantiation. Not all clients are patients though. Therefore, while Johanna is an instantiation of the player universal that plays the role of patient (let us call it a "client as a patient"), not all clients are "client as a patient". As Johanna does play the role of patient, the instantiation of the role universal 


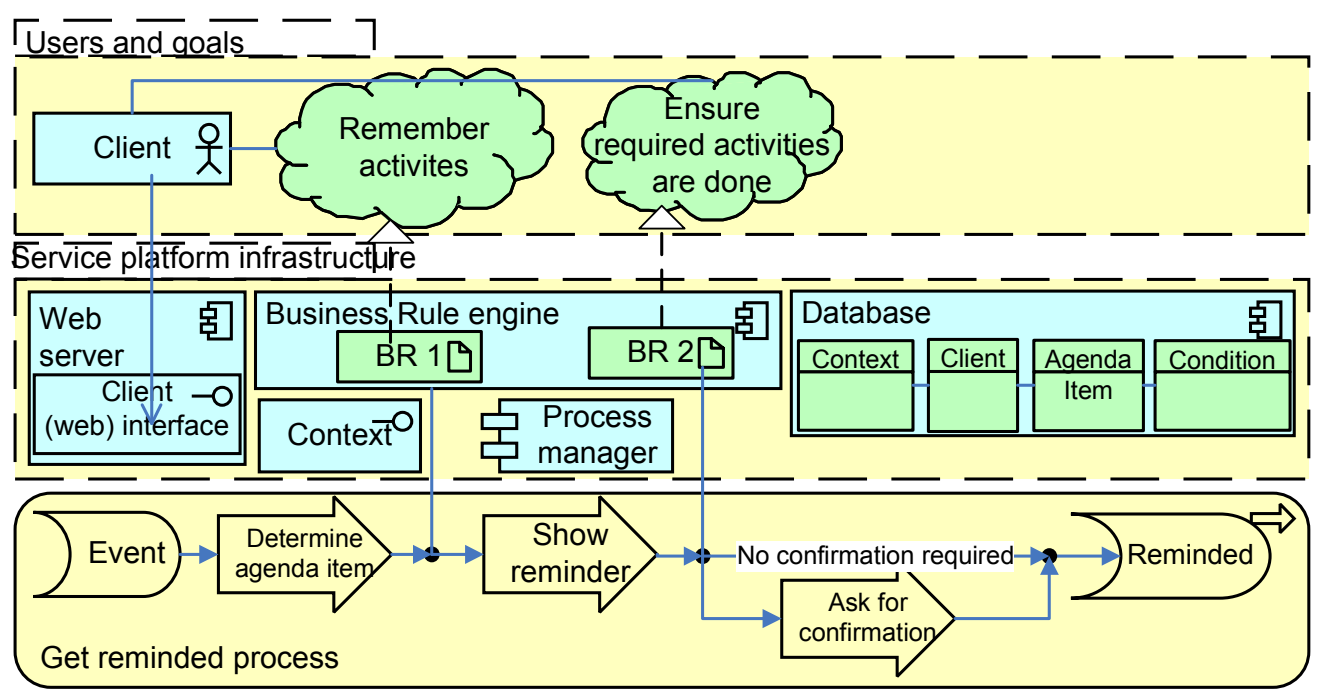

Figure 12. ArchiMate model for the reminder service.

patient also exists. We call this role individual "ThePatientJohanna". Player universals are stakeholders if they have a stake. In the case of "client as a patient", that may be the goal to "ensure required activities are done", for example remember to take medicines (see Fig. 13).

Resources linked to the stake may be tangible (e.g. medicines, alarm clock, and the components of the service platform infrastructure) or intangible (e.g. time and health). The resource are used or influenced by behavior, for example the "get reminded" process. It realizes a service by conducting activities that are part of it, for example "determine agenda item". The process defines part of the role of serviceProviderRole, namely the reminderRole. Both are a role in which the context is the natural universal client. Amongst others, home care organizations may play the serviceProviderRole. The reminderRole could be played by the natural universals human (for example the nurse) or, as this case suggests, an information system.

The perspective of the $\mathrm{HH}$ home care organization is most suitable for business modeling, as it is the only "business" in this case. HH home care is an instantiation of the home care organization that is the context for the patient role. The BMO does not include the business itself. The patient role, however, is a client relationship. It connects client segments to the value proposition. The identified client segment is the natural universal (Client) of the player universal ("Client as a patient") playing the role universal (Patient). The value proposition consists of the stake ("Ensure required activities are done", or more specific "Must take medicines) and the service providing the solution (Reminder service). To achieve the value proposition, the home care organization must perform the key activities with the key resources. The key activities are the behavior concepts from the RMM (e.g. take medicines, the get reminded process as a whole, or the individual activities such as determine agenda item). The key resources are the resources from the RMM (the components of the service platform infrastructure, medicines, etc.). Partners in the partner network are player universals that play a supplying role where key activities or key resources are the context. For HH home care, this may be the suppliers of the infrastructure. Cost structure and revenue structure have no corresponding concept in the RMM. The costs can be derived from the (costs to acquire) resources. Distribution channel has no corresponding concept in the RMM; however, a business interface from ArchiMate indicates such a channel.

\section{CONCLUSIONS AND DISCUSSION}

With the RMM, based on the practice of existing modeling languages and ontological analysis, we have defined several role-related concepts and their relations that

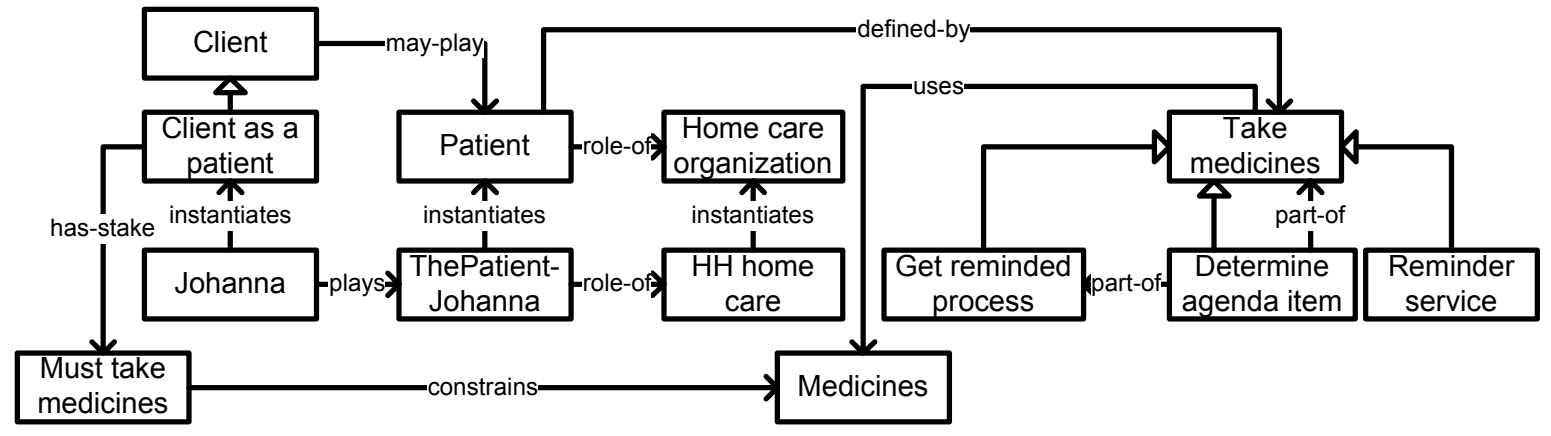

Figure 13. Partial instance of the RMM for the example of Johanna 
are important in business modeling. The RMM enables the knowledge captured by models to be transferred correctly. This forms a basis for creating comparable, formal business models, which enable further enterprise engineering, in a repeatable way. Johanna's case illustrates that the concepts in the RMM closely match those of both business modeling and enterprise engineering. The RMM can form the transition from a business model to an enterprise architecture model. This should help us avoid building economically nonviable systems, since their design is based on (and derived from) a viable business model.

As can be seen from the mapping to both the ArchiMate meta-model and the BMO, the RMM does not cover all concepts. From ArchiMate mainly the information aspects have no mapping, while from the BMO the financial aspects and the distribution channel are not present. An effort can be made to incorporate these concepts by extending the RMM. Such an extension is most interesting for concepts that are important in both worlds. BMO's distribution channel, for example, seems to relate to ArchiMate's business interface.

This version of the RMM decides on some debatable subjects. Two of those relate to the position of the relations and will be given some extra attention here. The first issue is to which concept(s) the has-stake-relation should be attached. At first thought, this could be any (and all) of the player and role concepts. The choice for player instead of role indicates that we think of roles as a grouping of behavior, and behavior does not have a stake. We made the choice for player universal instead of individual as the individual also has the stake of the universal. Besides that, for stakeholder analysis the interest is on the player universals usually, and not on the individuals. The stakes of individuals are abstracted to those of the universals.

The second issue for debate is whether behavior is (part of the) context of a role. In the RMM, this does not seem to be the case, as roles are a grouping of specific behavior and still have a context. Loebe [4], on the other hand, claims processes supply the context for processual role. He argues that the role-of-relation in case of a processual role is a specialization of the part-of-relation. As processes are a specialization of behavior, behavior is the context in that case. Our view can be reconciled with Loebe's by stating that behavior may be one of the concepts that can be a context, in the same manner that any natural universal may be the context. With this solution, the model may hold for other relation types than processual too.

The use of the (non-word) "Client as a patient", "ThePatientJohanna", "reminderRole", and "serviceProviderRole" terms indicates that in natural language the same terms are often used for different concepts. Which concept is meant must often be derived from the words around it. While using the RMM will help, it will remain difficult in practice, as everybody has his or her own connotation for words. This also makes it hard to grasp some of the concepts.

While the RMM is a step towards reducing pilot-illness, it is merely a part of the solution for viable IT innovation. A method to use the RMM is required still to reduce costs. If this method for designing systems and services is to replace the technology push style, it needs viable business models as input. A bad business model will still lead to an unviable solution; garbage in, garbage out.

\section{ACKNOWLEDGMENT}

This work is part of the IOP GenCom U-Care project, which is sponsored by the Dutch Ministry of Economic Affairs under contract IGC0816.

\section{REFERENCES}

[1] J.P. Almeida and G. Guizzardi, "A semantic foundation for rolerelated concepts in enterprise modelling," Enterprise Distributed Object Computing Conference, 2008. EDOC'08. 12th International IEEE, 2008, pp. 31-40.

[2] G. Genilloud and A. Wegmann, "A foundation for the concept of role in object modelling," Proc. Int'l EDOC Conf. 2004.

[3] ISO/IEC 42010:2007, Systems and software engineering: Recommended practice for architectural description of softwareintensive systems, 2007.

[4] F. Loebe, "Abstract vs. social roles-Towards a general theoretical account of roles," Applied Ontology, vol. 2, 2007, pp. 127-158.

[5] A. Osterwalder, "The Business Model Ontology-a proposition in a design science approach," Academic Dissertation, Universite de Lausanne, Ecole des Hautes Etudes Commerciales, 2004.

[6] The Open Group, ArchiMate 1.0 Specification, The Open Group, 2009.

[7] H. Zhu and M.C. Zhou, "Roles in information systems: A survey," IEEE Transactions on Systems Man and Cybernetics-Part CApplications Reviews, vol. 38, 2008, pp. 377-396. 